Pediat. Res. 2: 464-478 (1968)

Cystic fibrosis of the

pancreas

membrane transport salt metabolism sweat gland sweat rate

\title{
Sweat Composition in Relation to Rate of Sweating in Patients with Cystic Fibrosis of the Pancreas
}

\author{
H.M. Emrich, E.Stoll, B. Friolet, J.P. Colombo, R. Richterich and E. Rossi ${ }^{[72]}$ \\ Department of Pediatrics, University of Berne, Switzerland, and \\ the Department of Physiology, Free University of Berlin, Germany
}

Extract

Single sweat droplets were collected from a mineral oil-covered finger surface (fig. 1). Rate of sweat production (sweat rate) per gland per hour was calculated. Using microtechniques, the concentrations of electrolytes and metabolites, osmolarity, $\mathrm{pH}$, and viscosity were determined in undiluted pooled sweat. The following results were obtained:

No significant difference was observed in sweat rate per gland between control subjects and patients with cystic fibrosis of the pancreas (CFP).

Concentrations of sodium and chloride in sweat rose with increasing sweat rates in both control subjects and patients with CFP. In the patients with CFP, the lowest values were between 70 and 90 $\mathrm{mEq} / \mathrm{l}$ and the curve approached isotonicity. Chloride values were consistently lower than those of sodium. Concentrations of potassium decreased with increasing sweat rate in control subjects approaching a value of about $10 \mathrm{mEq} / 1$. In patients with CFP, the values for potassium were frequently twice as high as those in the control subjects. Concentration of calcium dropped rapidly with an increasing sweat rate from 10 to $1-2 \mathrm{mEq} / \mathrm{l}$.

Concentrations of lactic acid and urea were high at low sweat rates and decreased hyperbolically with increasing rates. In patients with CFP, the values of both components were lower than those in control subjects. Urea was uniformly more concentrated in sweat than in plasma; the sweat:plasma ratio approached 1.0 with increasing sweat rates.

Greatinine concentrations decreased with increasing sweat rate. No difference was observed between values in two patients and two control subjects. Glucose concentration was low $(0.2-6 \mathrm{mg} / 100$ $\mathrm{ml}$ ) and was independent of the sweat rate. No significant difference was observed in comparing five patients with CFP and six control subjects.

In control subjects, osmolarity decreased, with increasing sweat rate, from 240 to approximately $120 \mathrm{mOsmol} / \mathrm{l}$ and then increased (mean $163 \mathrm{mOsmol} / \mathrm{l}$ ). In patients with CFP, the curve was similar in shape but began and ended in a range of approximately $320 \mathrm{~m} / \mathrm{Osmol} / \mathrm{l}$ (mean $299 \mathrm{mOsmol} / \mathrm{l}$ ).

The $\mathrm{pH}$ of sweat was acid at low sweat rates $(\mathrm{pH} 3.5-6.0)$ and was slightly alkaline ( $\mathrm{pH} 7.0-8.5)$ at high rates. No differences were observed when comparing five patients and five control subjects.

$V$ iscosity of sweat was significantly elevated in five patients with CFP in relation to that observed in eight control subjects. This may be explained by the elevated concentration of salt in sweat of patients with CFP.

The excretory pattern of urea, lactic acid, and creatinine in sweat of patients with CFP, compared with that of control subjects, argues against an increased rate of water reabsorption in the excretory ducts of the sweat gland. The course of the sodium and the chloride curve and the values of osmolarity 
in sweat favor the assumption that in cystic fibrosis of the pancreas, the precursor fluid is in the isotonic range; net sodium reabsorption can then be calculated and appears to be defective in patients with this disease.

\section{Speculation}

It was shown that the concentration of most of the components of sweat vary with rate of sweating. This dependence on rate must be considered in studies on the effect of such variables as sex and age of the person, season, diseases, or drugs on composition of sweat. If this is not done, changes in rate may mask or exaggerate changes in concentration of the components of sweat. The introduction of improved methods for analysis of sweat over a broad range of rates may open for clinical investigation the problem of heterozygosity in cystic fibrosis of the pancreas.

\section{Introduction}

The demonstration of abnormally high concentrations of sodium and chloride in sweat of patients with cystic fibrosis of the pancreas has provoked several attempts to elucidate the cause of the defect [50]. This defect has been localized by some investigators in the coil $[22,23,58,59,60]$, and by others in the excretory duct of the sweat gland $[11,46,61,64]$. Schulz et al. [52, 53] have shown, by micropuncture technique, that in healthy persons an isotonic precursor fluid is formed in the coil. Sodium reabsorption in the excretory duct has been found to be responsible for the formation of hypotonic sweat [52, 53]. To obtain information on the basic nature of the defect of sweat formation in cystic fibrosis of the pancreas, the excretion of electrolytes and metabolites in relation to rate of sweat production (sweat rate) was investigated. Evidence pointing to a defect in sodium reabsorption in the excretory duct was obtained. Methods which permit the analysis of undiluted sweat were used [15]. This technique allows measurement of sweat rate per gland. Anaerobic sweat collection under mineral oil has been used previously by Brusilow $[4,5]$ and by SLegers [62].

Methods
Subjects
Two groups were studied : patients with cystic fibro-
sis of the pancreas (CFP) and control subjects (CS).
Sweat collection
After careful cleaning and drying of the skin, the
subject's hand was fixed in a molded plaster cast and
completely covered with mineral oil (fig. 1 A). Using
oblique illumination and a stereomicroscope, the
sweat droplets which appeared singly at the openings
of the excretory ducts on the extensor surface of the
fingers could be easily seen and counted (fig. 1 B). As
soon as droplets reached a reasonable size, just prior

to fusion, they were aspirated using a siliconized glass capillary filled, with mineral oil. Depending on sweat rate, between 60-250 droplets were collected as one sample, containing 5-10 $\mu \mathrm{l}$. The pooled sweat was blown into a mineral oil-filled cavity on a glass microscope slide. This method avoids air contact, evaporation, or contamination of the sample. The sample volume was measured using calibrated capillary pipettes [40]. The mean sweat rate/gland/hour was calculated from the volume of the sample divided by the number of aspirated droplets, which corresponded to the number of glands active during the sampling period. The sampling period was the time interval between the immersion of the hand under mineral oil and the middle of the collecting period.

\section{Sweat Stimulation}

Stimulation was initiated prior to washing and immersion of the hand; in this way, sweat rate was relatively constant. Minimal rates were obtained at room temperature without stimulation. Consumption of hot tea produced slightly higher rates. Medium rates were provoked by application of infrared heating locally or to the whole body. Peak rates were achieved by pilocarpine iontophoresis [21]. The experiments were performed on boys, aged 6-12 years, in the morning during the summer. The number of control subjects (CS) and patients (CFP) varied in the different examinations as indicated in the tables and figures.

\section{Chemical Methods}

In the text which follows, the volumes used for analysis are given in parentheses. Sodium $(1.0 \mu \mathrm{l})$, potassium $(2.0 \mu \mathrm{l})$, and calcium $(2.5 \mu \mathrm{l})$ were measured by flame photometry using an Eppendorf photometer. Chloride $(0.3 \mu \mathrm{l})$ was assayed by microelectrotitration according to the method of RAMSAY, BROWN and CROGHAN [44], using a modified Beckman microtitrator model 153 [19]. Osmolarity was measured by 
microcryoscopy [43]. Urea $(0.5 \mu \mathrm{l})$ was determined using the DAM-PAA method [3]. Lactic acid $(1.0 \mu 1)$ was assayed by a micromodification of the enzymatic method of Gercien [20]. Creatinine $(5.0 \mu \mathrm{l})$ assays were performed by the method of SLOt [66]. Glucose $(4.0 \mu \mathrm{l})$ was measured enzymatically using a micromodification of the glucose oxidase method of RichteRIGH and Colombo [45]. A miniaturized Ostwald flow viscosimeter was used for the determination of viscosity $(4.8 \mu \mathrm{l})$. Calibration was performed by the use of standard solutions. The $\mathrm{pH}(1.0 \mu \mathrm{l})$ was assayed, using a quinhydron electrode as described previously [16].

\section{Design and Statistical Analysis of the Experiments}

The purpose of this study was to obtain reliable information on the kinetics of the excretion of several components of sweat. The kinetic studies required analysis of multiple samples from single individuals at different sweat rates with short sampling periods. For this reason, it was not feasible to pair control and patient samples. When enough observations in both groups were made over a defined range of sweat rates, mean values were statistically compared, using Student's t-test [47]. Such comparisons were made for lactic acid, urea, creatinine, and glucose.

The medium curves for sodium and chloride concentration were derived by the following method [15]. Straight lines were obtained if the logarithms of the difference between the sodium concentration of primary sweat (147 mEq/1) [53] and the sodium concentration in final sweat were plotted against different sweat rates (fig. 3 ). From these regressions, the mean curves in figures 2 and 3 were calculated. The method of construction of the hyperbolic curves (lactic acid, urea, calcium, and potassium) has been described previously [15].

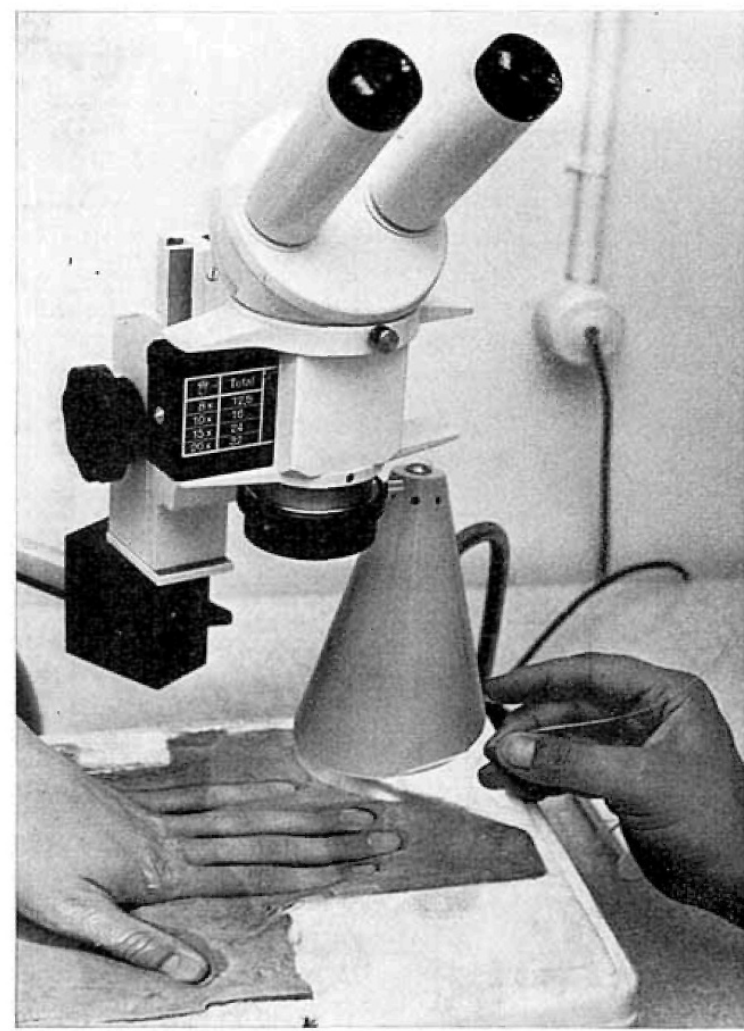

$1 A$

Fig. 1. Technique for sweat collection. $A$. The hand of the subject is fixed in a molded plaster cast filled with mineral oil. $B$. Single sweat droplets on the skin surface covered with mineral oil. Glass capillary.

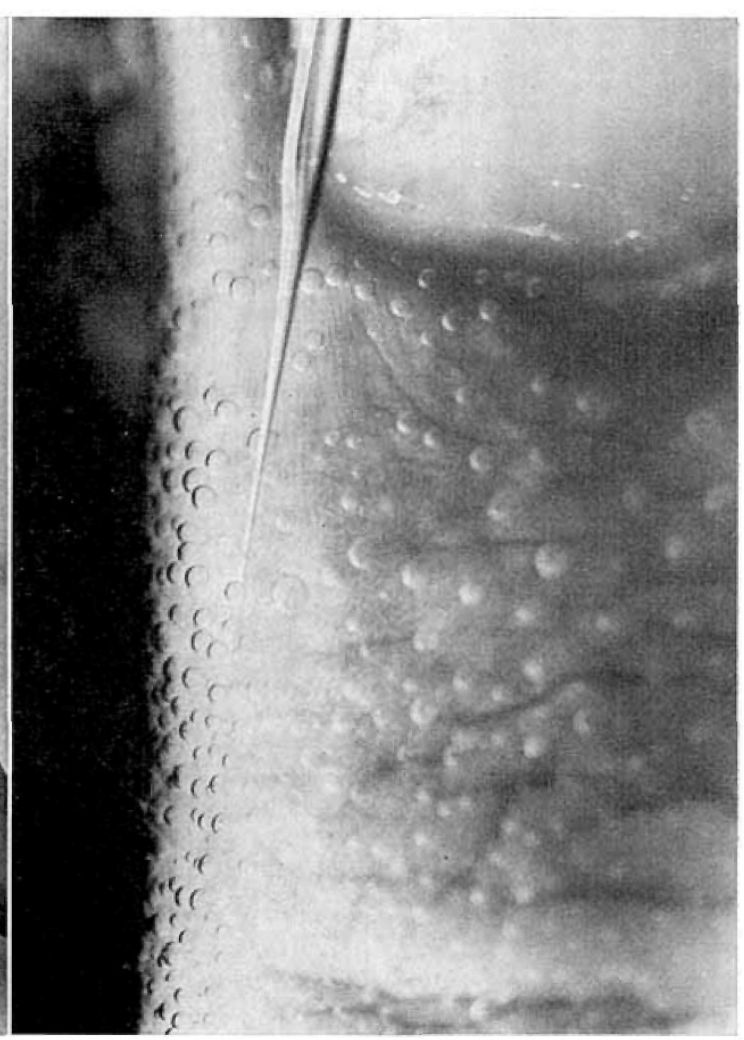

$1 B$

Fig. 2. Concentration of sodium (A) and chloride (B) in sweat plotted in relation to rate of sweating per gland. Open symbols: 4 patients with CFP; black symbols: 4 control subjects. 

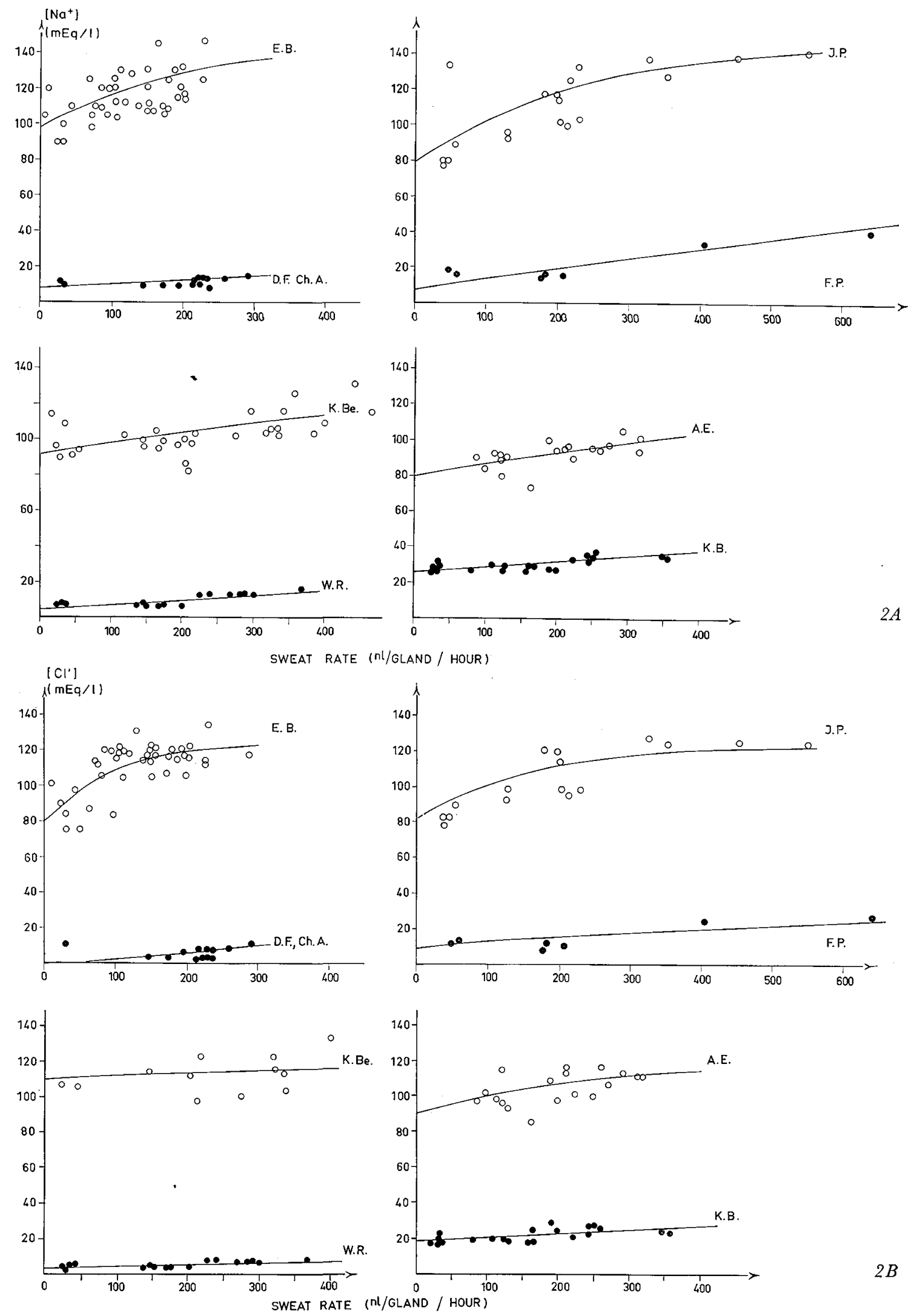


\section{Sreat Rate}

Results

Following three different types of stimulation, no significant difference in sweat rate was observed between CS and CFP (table I). In children before puberty, the sweat rate per gland following pilocarpiniontophoresis was lower than the rate of adults under the same circumstances. LOBECK and McSherRy [33] have made the same observation using different techniques.

Sodium

In ten $\mathrm{CS}$, there was a rise from very low values (10-20 $\mathrm{mEq} / \mathrm{l})$ with increasing sweat rate. In nine CFP, the lowest values were approximately 70-90 $\mathrm{mEq} / \mathrm{l}$, and the curve approaches isotonicity (figs. 2 and 3).

Sodium concentrations of $60-190 \mathrm{mEq} / \mathrm{l}$ have been reported in sweat of patients with cystic fibrosis of the pancreas [50]. We have never encountered concentrations above isotonicity $(145 \mathrm{mEq} / \mathrm{l})$. Methodological differences are probably responsible for this discrepancy. As pointed out by Dobson [14], all errors in commonly used methods for sweat analysis $[13,21]$ tend to produce positive errors: evaporation from skin surface, contamination of filter paper discs, and the use of sodium containing filter paper. A more important systematic error is introduced by a failure to recognize the effect of sweat rate on sodium concentra-
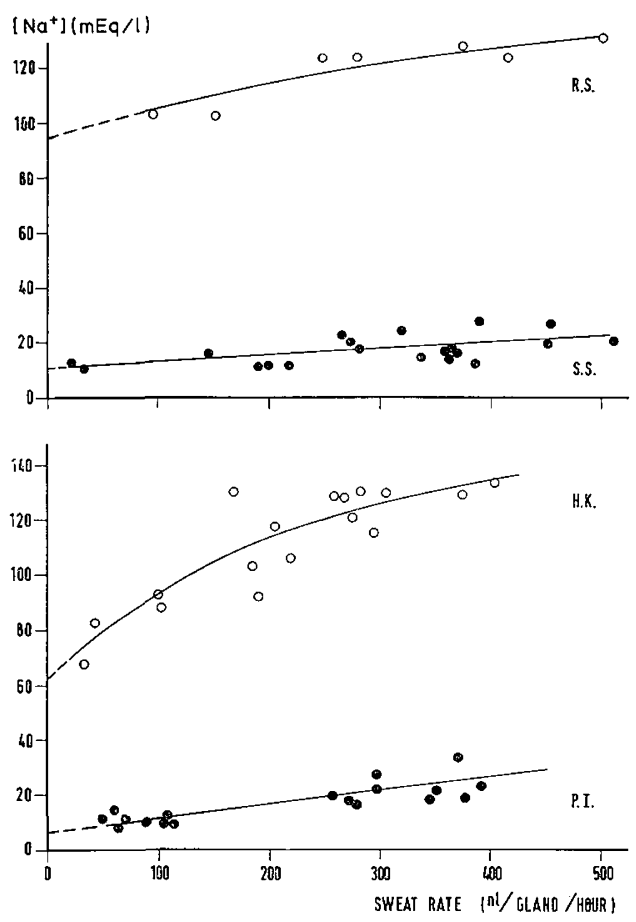

Table I. Mean values of sweat rates following three different kinds of stimulation ${ }^{1}$

\begin{tabular}{|c|c|c|c|}
\hline \multirow{2}{*}{$\begin{array}{l}\text { Kind of } \\
\text { stimulation }\end{array}$} & Patients & \multicolumn{2}{|c|}{ Normal controls } \\
\hline & \multicolumn{3}{|c|}{$\mathrm{nl} /$ gland/h } \\
\hline $\begin{array}{l}\text { No stimulation } \\
\text { or hot tea }\end{array}$ & $\begin{array}{l}42 \pm 35 \\
(65)\end{array}$ & $\begin{array}{c}53 \pm 34 \\
(47)\end{array}$ & $\mathrm{p}>0.1$ \\
\hline $\begin{array}{l}\text { Infrared } \\
\text { application }\end{array}$ & $\begin{array}{c}125 \pm 58 \\
(104)\end{array}$ & $\begin{array}{c}147 \pm 85 \\
(49)\end{array}$ & $\mathrm{p}>0.5$ \\
\hline $\begin{array}{l}\text { Pilocarpine } \\
\text { iontophoresis }\end{array}$ & $\begin{array}{l}285 \pm 137 \\
(202)\end{array}$ & $\begin{array}{l}274 \pm 111 \\
\quad(112)\end{array}$ & $\mathrm{p}>0.4$ \\
\hline
\end{tabular}

1 Values given are mean and standard deviation of the mean; figures in parentheses refer to number of observations.

Fig.4. Concentration of potassium in sweat plotted as a function of rate of sweating per gland. A. Black symbols: 7 control subjects. $B$. Open symbols: 8 patients with GFP.

Fig. 3. A. Concentration of sodium in sweat as a function of rate of sweating per gland. Open symbols : 2 patients with GFP; black symbols: 2 control subjects. $B$. Ordinate: logarithm of the difference between sodium concentration in the precursor fluid $(147 \mathrm{mEq} / \mathrm{l})$ and sodium concentration in sweat. Abscissa : rate of sweating.

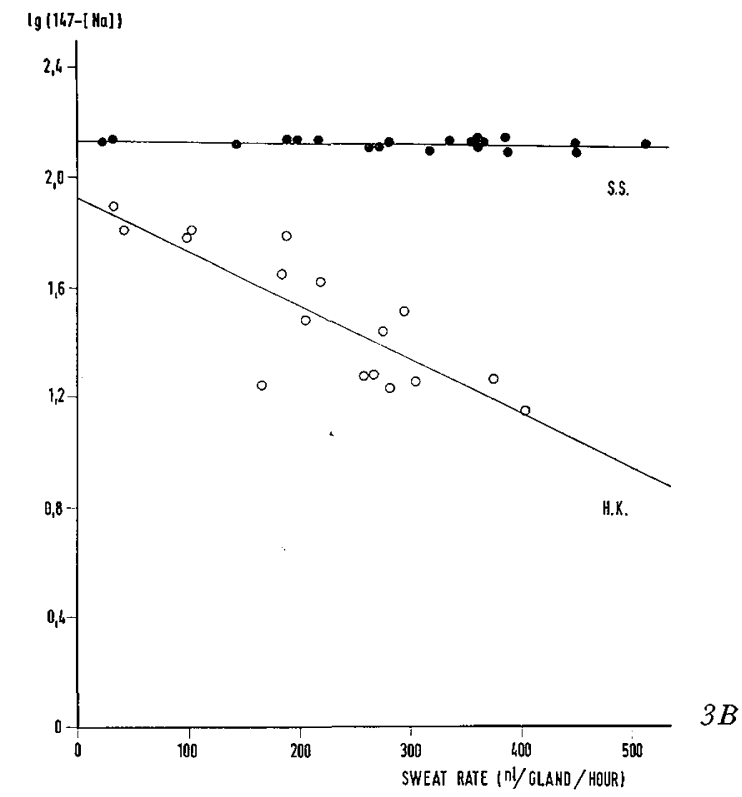


Sweat composition in relation to rate of sweating in patients with cystic fibrosis of the pancreas 469 POTASSIUM CONCENTRATION (mEq / 1 )
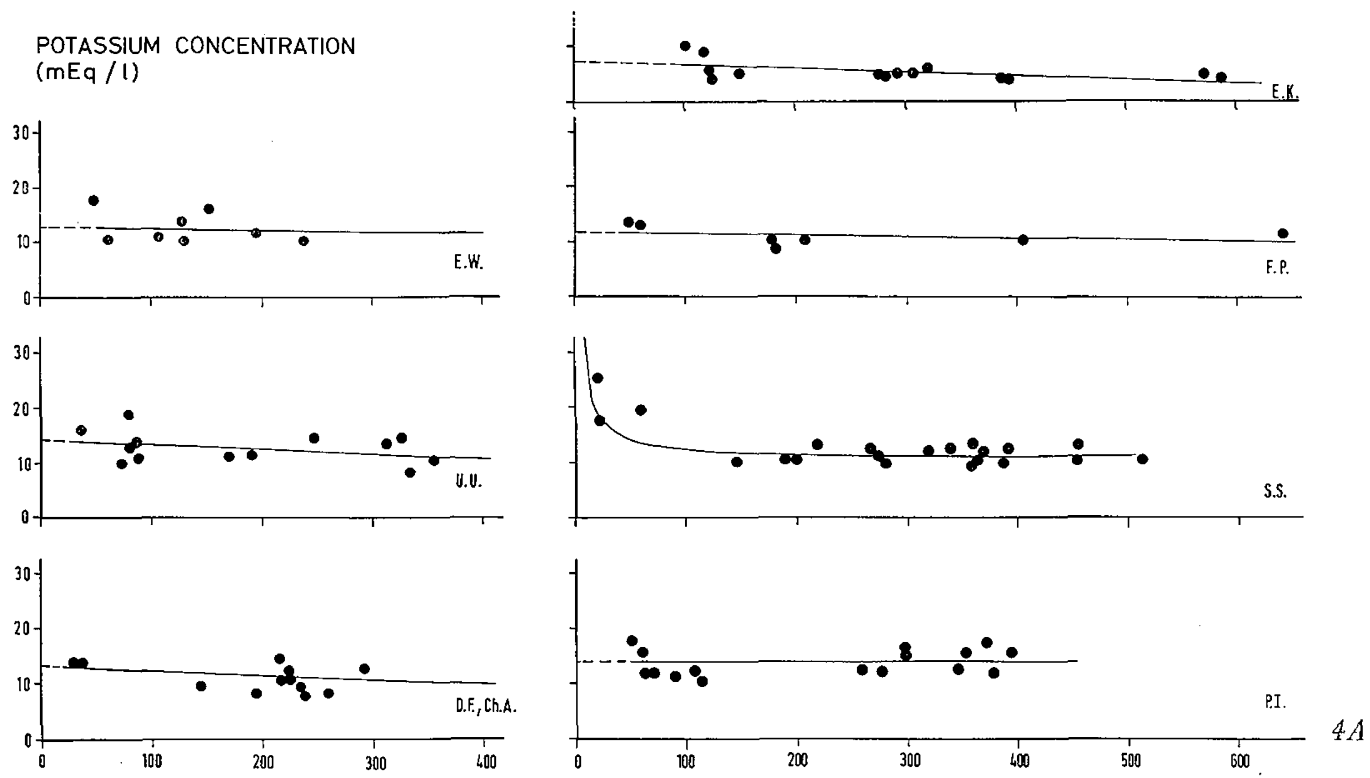

POTASSIUM CONCENTRATION ( $\mathrm{mEq} / \mathrm{l}$ )

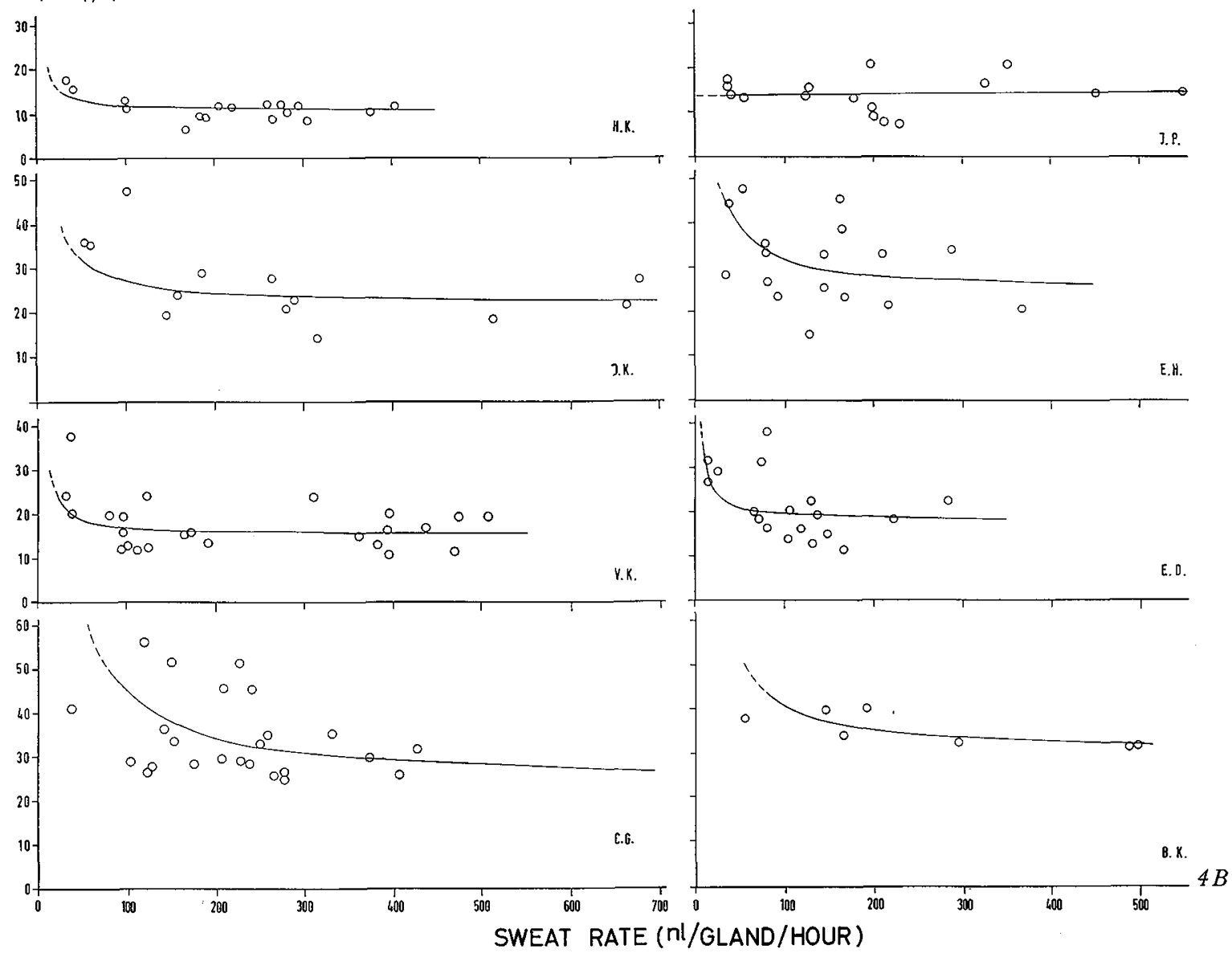

32 Pediat. Res., Vol. 2, No. 6 (1968) 
tion; sodium concentration increases significantly with increasing rate of sweating $[10,15,33]$. If this effect of sweat rate is considered, the biological variability decreases and amounts to $\pm 15 \mathrm{mEq} / \mathrm{l}$ (maximal dispersion of values) at all sweat rates in both control subjects and patients with cystic fibrosis of the pancreas.

\section{Chloride}

Chloride values behaved like those of sodium but were consistently lower. In CFP, at high sweat rates, the chloride curve approached a value of about 120 $\mathrm{mEq} / \mathrm{l}$. For practical purposes, the highest chloride concentrations in sweat corresponds to plasma concentrations when a correction is made for the Donnan equilibrium (fig. 2).

\section{Potassium}

The concentration of potassium decreased with an increasing sweat rate. In seven CS, the potassium concentration approached a value of $10 \mathrm{mEq} / \mathrm{l}$. In two of eight CFP (H.K. and I.P.), the potassium concentration was within normal range; in the remaining six patients, it was definitely elevated (fig. 4).

Di SANT'Agnese [50] reported elevated concentrations of potassium in sweat of patients with cystic fibrosis of the pancreas. As observed by several investigators [32] and demonstrated in our study, this finding is not as constant as is the elevated concentration of sodium. Richterich and Friolet [46] attempted to explain the increased concentration of potassium in sweat of patients with cystic fibrosis of the pancreas by postulating a transport mechanism in the excretory duct involving proximal sodium reabsorption and distal sodium-potassium exchange. Assuming a defect in proximal sodium reabsorption, more sodium will be presented for the distal exchange mechanism. Slegers [65] has recently elaborated this hypothesis by using a mathematical approach. Further evidence for the existence of a sodium-potassium exchange was obtained from experiments with aldosterone. In normals, as well as in patients with cystic fibrosis of the pancreas, aldosterone causes a decrease in concentration of sweat sodium accompanied by an increase in concentration of potassium [18, 24, 25, 51].

\section{Calcium}

Calcium concentration dropped rapidly with increasing sweat rate from above 10 to $1-2 \mathrm{mEq} / \mathrm{l}$. At high rates, the calcium concentration appeared to be higher in sweat from CFP than in sweat from CS. The number of determinations was not sufficient for statistical treatment (two patients, five control subjects) (see fig. 5).

Our observations are generally in agreement with findings of other investigators [49]. Profuse sweating

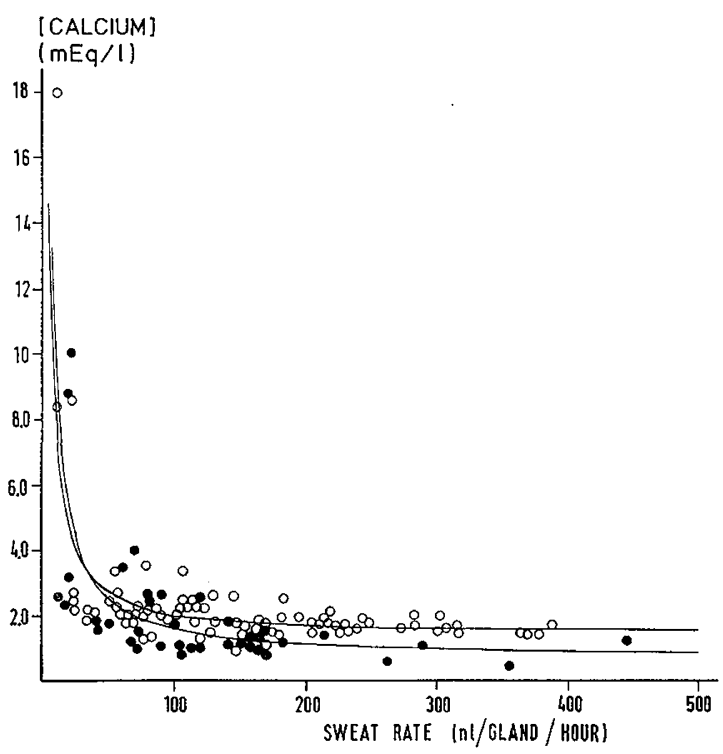

Fig. 5. Concentration of calcium in sweat plotted as a function of rate of sweating per gland. Open symbols: 2 patients with CFP; black symbols : 5 control subjects.

leads to lower concentrations of calcium than does minimal sweating [41]. At low sweat rates, calcium concentration in our experiments was considerably higher than that observed by other authors [49]. This was probably due to an improved sampling method. The observations regarding sweat of patients with cystic fibrosis of the pancreas are similar to findings in the parotid saliva fluid [39], but not in submaxillary saliva [12].

\section{Lactic Acid}

Lactic acid was more concentrated at low sweat rates and decreased hyperbolically with increasing rates. Figure 6 shows data from two CFP and three CS. At sweat rates from $0-150 \mathrm{nl} / \mathrm{gland} / \mathrm{h}$, the values in CFP were significantly lower than those in CS ( $p$ $<0.03$ ). Since there were few determinations in CS, no definite conclusion can be derived from this observation. The 10 - to 20 -fold increase in concentration of lactic acid in sweat, compared with that of plasma, excludes an origin of this metabolite from blood [2]. Measurements of anaerobic glycolysis of isolated sweat glands [52] and of the lactate: pyruvate ratios [17] suggest that lactic acid is formed in gland cells. Since concentration of lactic acid is comparable in CS and in CFP, a defect in the glycolytic potential of the sweat glands of CFP seems unlikely. 
Sweat composition in relation to rate of sweating in patients with cystic fibrosis of the pancreas 471

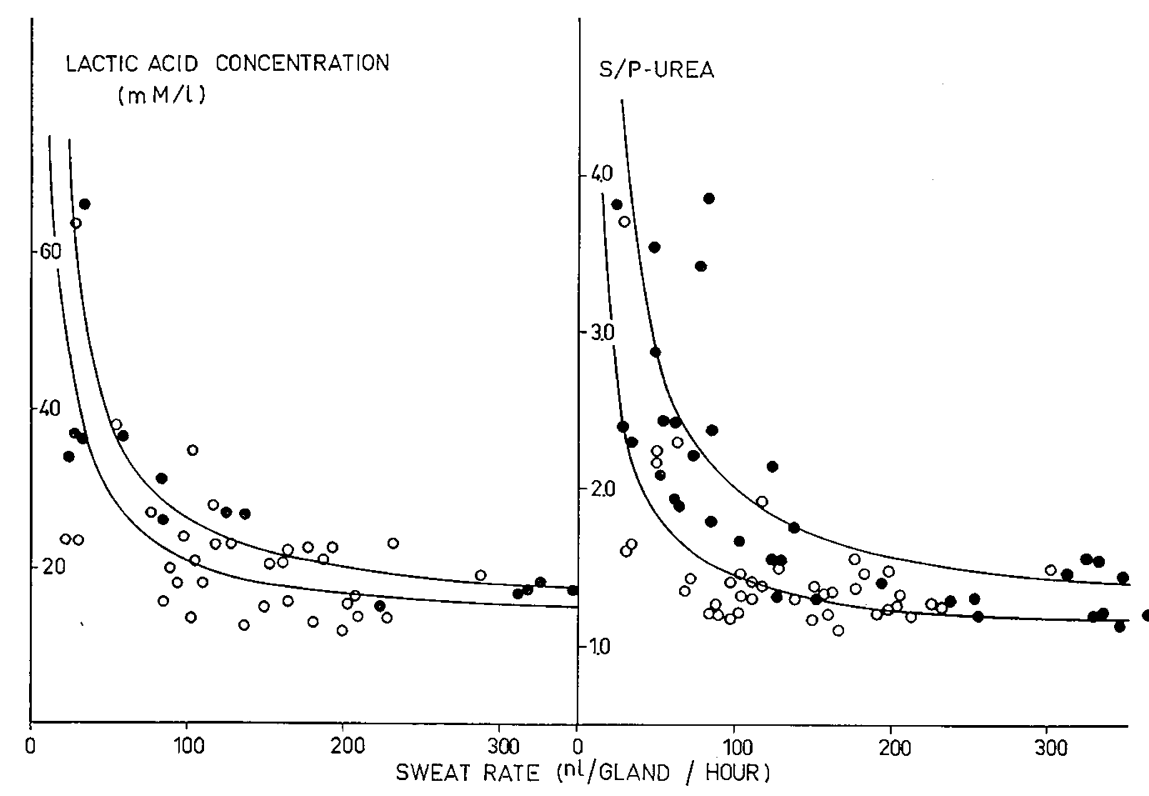

$6 A$
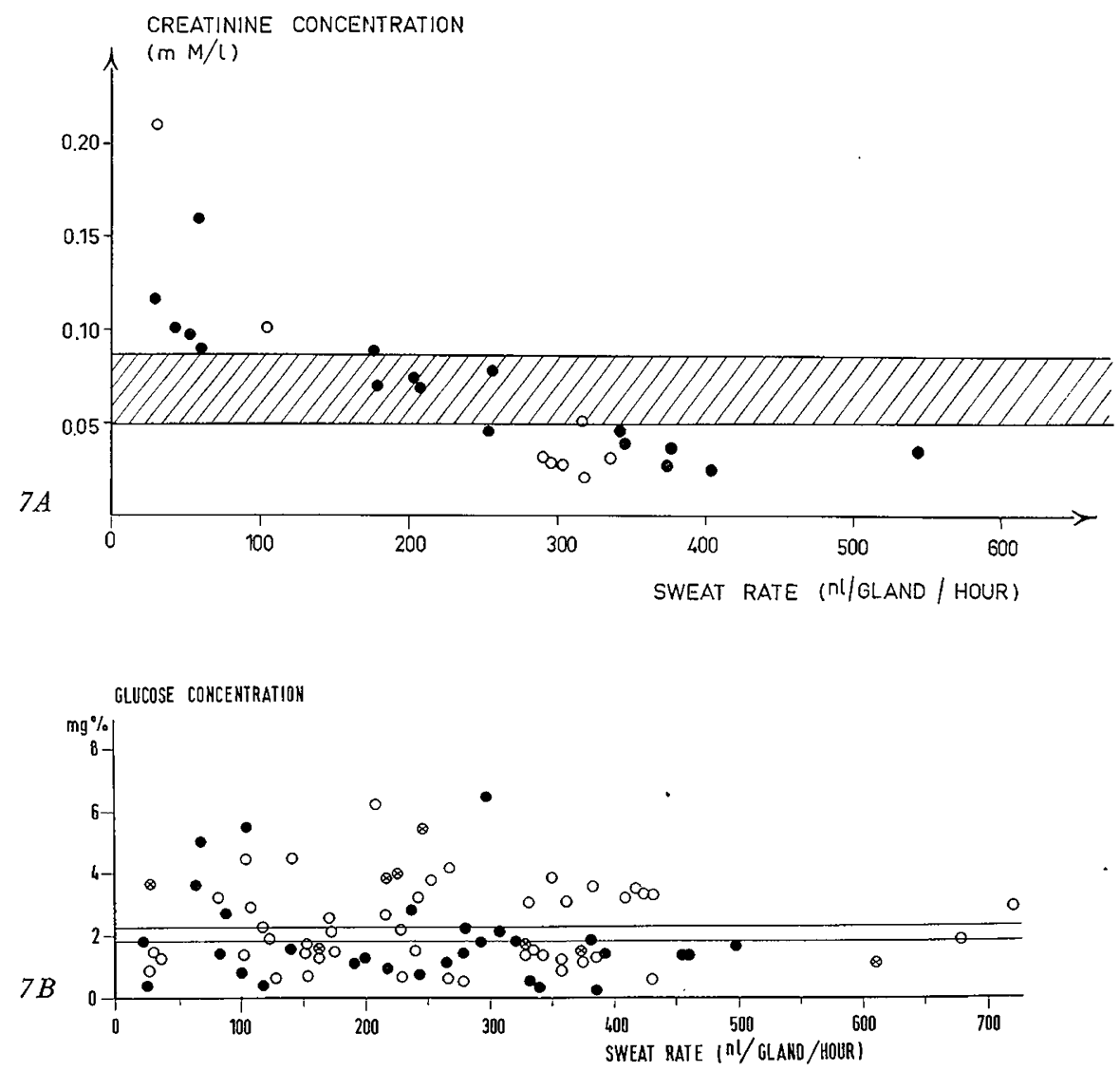

Fig.6. A. Concentration of lactic acid in sweat plotted as a function of rate of sweating per gland. Open symbols: 2 patients with CFP; black symbols: 3 control subjects. B. Relative urea concentration (sweat concentration/ plasma concentration) plotted as a function of rate of sweating per gland. Open symbols: 4 patients with GFP; black symbols : 4 control subjects.

Fig.7. A. Concentration of creatinine in sweat plotted as a function of rate of sweating per gland. Open symbols: 2 patients with GFP; black symbols: 2 control subjects. Cross hatched area indicates plasma concentration. $B$. Concentration of glucose in sweat plotted as a function of rate of sweating per gland. Open symbols: 5 patients with CFP; black symbols: 6 control subjects. Values obtained following intradermal injection of phloridzin $(15 \mathrm{mg} /$ $100 \mathrm{ml}$ ). 
Urea

Concentration of urea was high at low sweat rates and decreased hyperbolically with increasing sweat rate. At sweat rates between 0 and $100 \mathrm{nl} / \mathrm{gland} / \mathrm{h}$, the ratio of sweat: plasma concentration was significantly lower in four GFP than in four CS $(\mathrm{p}<0.005)$; again, no definite conclusion can be derived because of the limited number of observations (fig. 6). Urea was consistently more concentrated in sweat than in plasma, and the sweat:plasma ratio approached 1.0 with increasing sweat rates.

Other investigators $[1,9,36]$ have also observed a decrease of urea concentration with increasing sweat rate. Contradictory observations $[29,56,63]$ may be explained by the fact that the investigators used filter paper [56, 63] or a wash-down technique [29], neither of which permits sampling at very low sweat rates.

Of the several mechanisms which have been proposed to explain the pattern of urea excretion $[6,7,8,9$, 29], concentration of urea by water reabsorption in the excretory duct $[15,56,63,68]$ is the most consistent with our experimental observations. Because of the osmotic difference between the hypotonic sweat and the isotonic interstitial fluid, water diffuses from the excretory duct into the interstitial space. The kinetics of urea concentration are consistent with the assumption that water reabsorption is limited and approaches a finite value determined by permeability and osmotic differences between sweat and interstitial space. Thus, the water reabsorption rate will be inversely proportional to the sweat rate. This hypothesis [15] is supported by the following experimental observations:

1. Urea concentration was related inversely to sweat rate (fig. 6) as might be expected if water reabsorption were limited and back diffusion of urea were negligible.

2. Urea concentration was always higher in sweat than in plasma (fig.6). Even when urea concentration in plasma is increased by a urea load, the sweat: plasma ratio remains the same $[29,35,56,63,69]$.

3. When high sweat osmolarity is induced by local injection of ouabain, the sweat: plasma urea ratio decreases more rapidly [15].

4. The same effect was observed in CFP in whom an abnormally high sweat osmolarity occurs spontaneously (fig. 8).

These arguments may justify the use of relative urea concentration in sweat as an index for water reabsorption in the excretory duct. Since this hypothesis has been disputed $[7,8,29]$, it would be valuable to study other substances which might be used as markers of water movement within the gland.

\section{Creatinine}

Concentration of creatinine in sweat decreased at increasing sweat rates. There were no significant differ- ences between the results from two CS and from two CFP ( $p<0.25)$. In contrast to urea, only at very low sweat rates was creatinine concentration higher in sweat than in plasma (fig. 7). These results are in agreement with observations of others [13, 30, 49]. It is probable that because we studied much lower sweat rates than did other investigators, we also observed ratios of sweat: plasma concentration higher than 1.0. The difference between the patterns for creatinine and for urea may be due to any or all of the following: secretion of creatinine in sweat at concentrations lower than those that exist in plasma; nonionic diffusion (and trapping in acid sweat); water reabsorption.

\section{Glucose}

Concentration of glucose in sweat was between 0.2 and $6.0 \mathrm{mg} / 100 \mathrm{ml}$ and was independent of sweat rate. There was no significant difference between six CS and five CFP ( $p<0.20)$. Local injection of phloridzin $(15 \mathrm{mg} / 100 \mathrm{ml}$ ) did not affect glucose excretion (fig. 7).

Other investigators, using either reducing methods [28] or paper chromatography [13] for glucose administration obtained contradictory results. The independence of glucose concentration from sweat rate was first noted by Lobitz and OsteRberg [34]. In this regard, glucose differs from all other components in sweat. As glucose concentration in sweat is not elevated by intradermal injection of phloridzin, active glucose reabsorption in excretory ducts as in the kidney [67] seems unlikely. It is likely that the low concentration of glucose in sweat reflects passive diffusion of glucose into the duct lumen.

\section{Osmolarity}

In four GS, it was observed that osmolarity, when plotted as a function of sweat rate, dropped from about 240 to about $120 \mathrm{mOsmol} / \mathrm{l}$, and then rose again (mean: $163 \mathrm{mOsmol} / \mathrm{l}$ ). In four CFP, the curve was similar in shape but remained within the isotonic range (mean: $299 \mathrm{mOsmol} / \mathrm{l}$ ) (fig. 8). Since osmolarity is a function of dissolved particles, one must explain the shape of the osmolarity curves by examining the varying concentrations of osmotically active substances. Our experiments permit classification of the excreted substances into three categories: (1) those substances, the concentration of which increases with sweat rate (sodium and chloride); (2) those substances, the concentration of which falls with increasing sweat rate (potassium, calcium, lactic acid, urea, and creatinine); and (3) those substances, the concentration of which bears no relation to sweat rate (glucose). The algebraic sum of the mean of each of these concentrations for CFP and for CS generates a curve which corresponds in shape remarkably well to the observed points of osmolarity. In CFP, osmolarity can be ex- 
Sweat composition in relation to rate of sweating in patients with cystic fibrosis of the pancreas 473

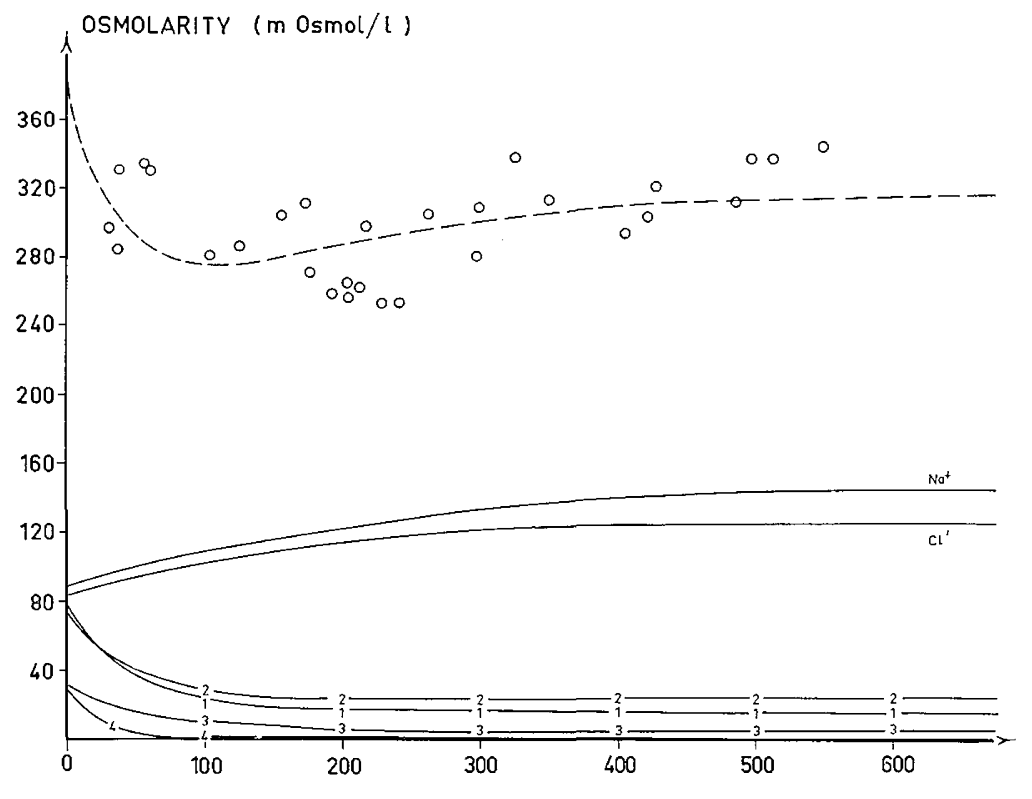

Fig. 8. Osmolarity in sweat plotted as a function of rate of sweating per gland. Open symbols: 4 patients with GFP; black symbols: 4 control subjects. Continuous lines: mean curves of measured substances; interrupted line: sum of measured substances.
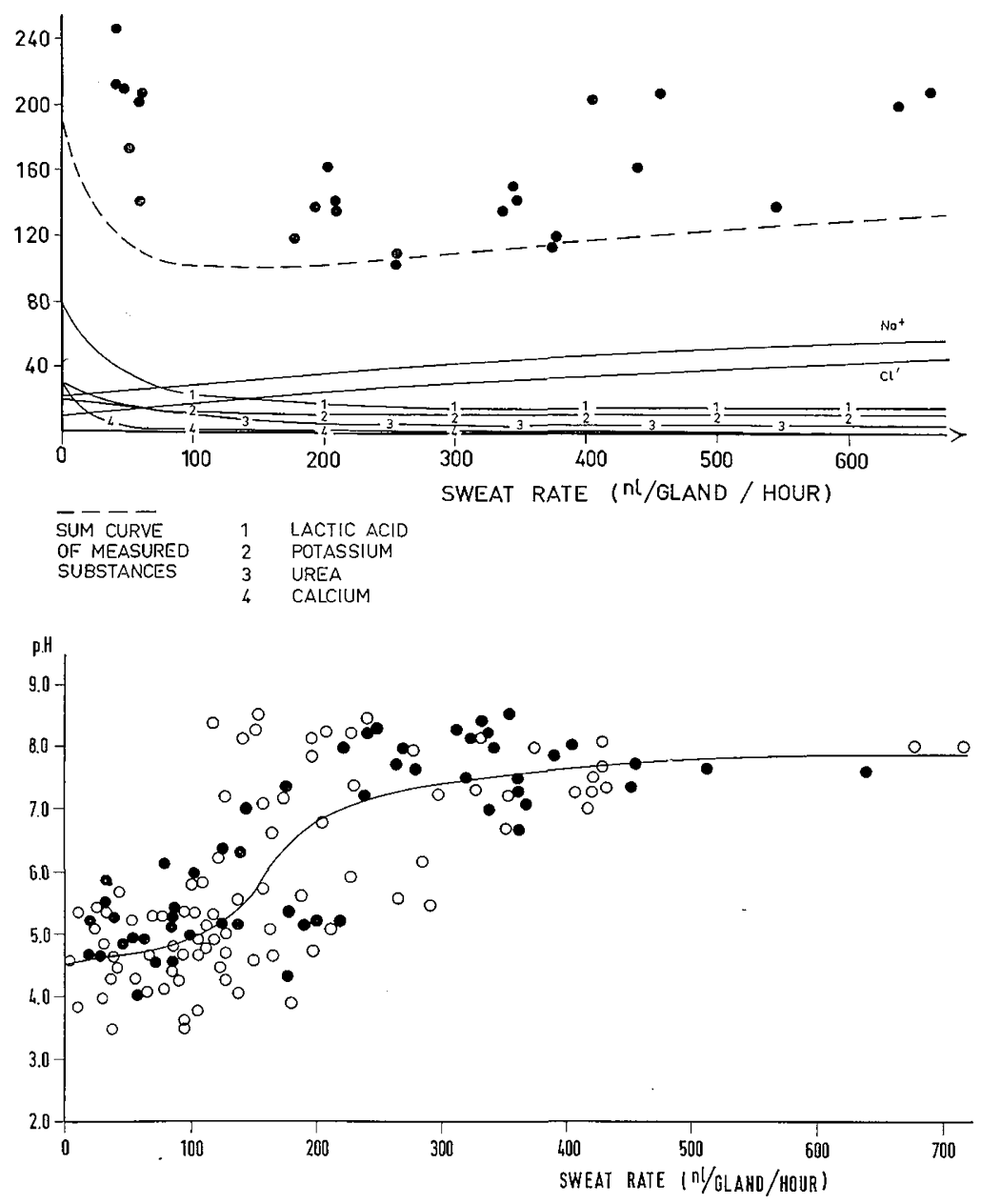

Fig. 9. The $\mathrm{pH}$ of sweat plotted as a function in rate of sweating per gland. Open symbols: 5 patients with GFP; black symbols: 5 control subjects. 
VISCOSITY at $30^{\circ} \mathrm{C}$

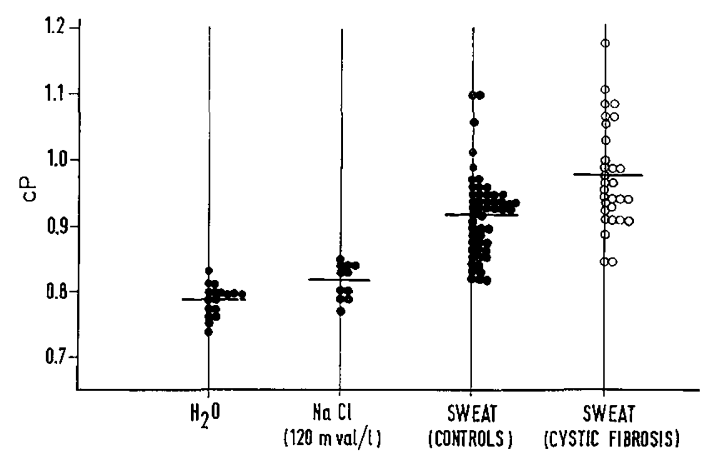

Fig. 10. Viscosity of sweat, water, and water with $\mathrm{NaCl}$ $(120 \mathrm{mEq} / \mathrm{l})$ at $30^{\circ}$. (5 patients with CFP and 8 control subjects.)

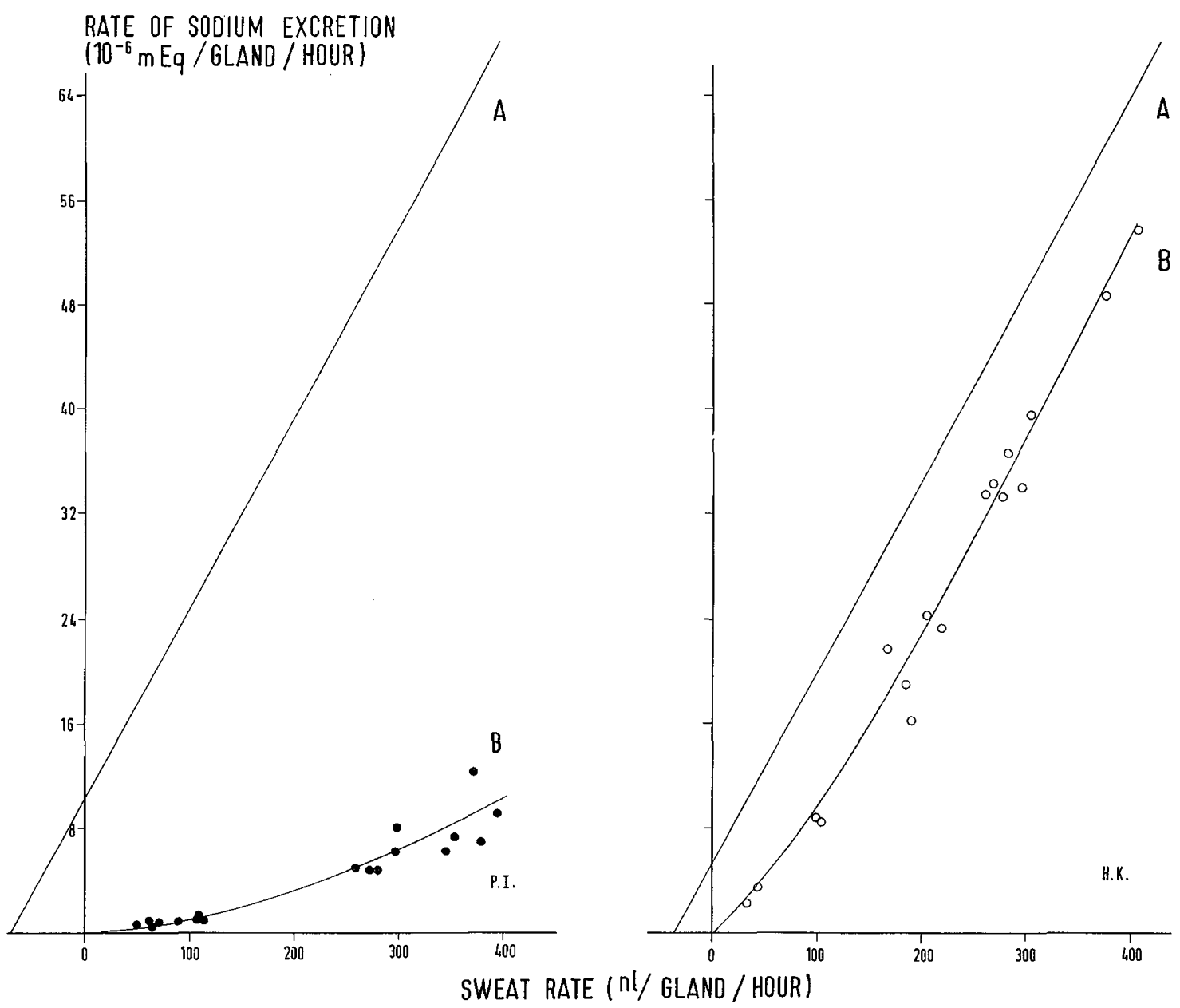

Fig. 11. Rate of sodium excretion (line B) plotted in relation to rate of sweating. Black symbols: control subject; open symbols: patient with CFP. Line A: Precursor fluid sodium rate, taking into account water reflux. Modified plot $[10,15]$. plained by the concentrations of the components analyzed. In GS, there exists a difference of about 40 $\mathrm{mOsmol} / \mathrm{l}$ between the calculated curve and the measured points. This difference is unexplained, but may reflect either technical problems in analysis or physiological variations as yet unidentified.

$p H$

In five $\mathrm{CS}$ and in five CFP, $\mathrm{pH}$ was low at low sweat rates (pH 3.5-6.0) and slightly alkaline at high rates (pH 7.0-8.5) [37, 38] (fig. 9). This observation may be explained by the lower concentration of lactic acid and, therefore, the lower buffer capacity at high sweat rates. The change in $\mathrm{pH}$ of sweat occurred at about the same sweat rate $(150 \mathrm{nl} /$ gland/h) at which lactic acid concentrations reached the lowest values of about $20 \mathrm{mM} / \mathrm{l}$ 
(fig. 6). If sweat is first equilibrated with a partial pressure of $40 \mathrm{~mm} \mathrm{Hg} \mathrm{CO}$, sweat is consistently acid [16]. The alkaline $\mathrm{pH}$ at high sweat rates can therefore be explained by a loss of $\mathrm{CO}_{2}$. This has been demonstrated by application of the Henderson Hasselbalch equation [16]. Abnormal bicarbonate concentration in sweat of patients with cystic fibrosis of the pancreas seems improbable since $\mathrm{pH}$ in sweat of these patients is the same as that of normal individuals.

Herrmann and Mandol [26] concluded that pharmacological stimulation leads to a production of alkaline sweat and thermic stimulation to production of an acid sweat. But more recent observations [16] agree with those of Heuss [27] and of MARGHIonini [37, 38]; who found that $\mathrm{pH}$ is a function of sweat rate and that maximal thermal stimulation also yields an alkaline sweat.

\section{Viscosity}

Viscosity of sweat at $30^{\circ}$ was between 0.9 and $1.2 \mathrm{cP}$ and was independent of sweat rate. In five GFP, the mean value was significantly higher than that in $8 \mathrm{CS}$ $(p<0.001)$. Since viscosity of an aqueous solution increases with salt concentration, values for sweat from patients with cystic fibrosis of the pancreas should be corrected for high salt concentrations. A difference in concentration of $120 \mathrm{mEq} / \mathrm{l}\left(\mathrm{Na}^{+}+\mathrm{K}^{+}\right)$corresponds to about $0.03 \mathrm{cP}$ (fig. 10). If this factor is considered, sweat viscosity of CFP is not significantly different from that of CS $(p<0.1)$.

Viscosity of sweat in CS and in CFP is about $0.1 \mathrm{cP}$ higher than is the viscosity of a salt solution of 120 $\mathrm{mEq} / 1$ (fig. 10). This discrepancy may be explained by the presence of mucoproteins which are known to be present in sweat $[42,57]$. The minimal difference between sweat from CS and from CFP can reasonably be explained by the marked differences in salt concentration.

\section{Discussion}

High concentrations of sodium and chloride in sweat of patients with cystic fibrosis of the pancreas can be explained by four different hypotheses [23].

\section{Increased Sweat Rate of Single Glands}

Since concentrations of sodium and chloride in sweat increase with increasing sweat rate $[10,15,31,55]$, high concentrations could be explained by an abnormal population of sweat glands characterized by an abnormally high flow rate (hypersecretion hypothesis) [48]. According to our results (table I), there is no significant difference in sweat rate between CS and CFP.

\section{Hypertonic Concentration of Sodium and Chloride in the Precursor Fluid}

That concentrations of sodium and chloride approach isotonicity at high flow rates in GFP (figs. 2 and 3 ) suggests that an isotonic precursor fluid is formed in the coil. This conclusion is in agreement with recent findings of SaHulz [54], who used a technique involving micropuncture of the coil.

Increased Rate of Water Reabsorption in the Excretory Duct If relative urea concentration is used as an index for water reabsorption, a rate can be estimated using the clearance principle [15]. In healthy adults, water reabsorption thus calculated is $90 \mathrm{nl} / \mathrm{gland} / \mathrm{h}$ [15]; in healthy children, $70 \mathrm{nl} /$ gland $/ \mathrm{h}$; and in patients with cystic fibrosis of the pancreas, $35 \mathrm{nl} / g$ land/h. These results negate the assumption of an increased water reabsorption. This conclusion is supported by the observation that concentrations of lactic acid, creatinine, and glucose are no higher in sweat of GFP than they are in sweat of CS.

\section{Defective Sodium Reabsorption in the Excretory Duct}

Since the difference in sweat composition in CS and CFP is quantitative rather than qualitative, an attempt was made to calculate the net sodium reabsorption rate in both groups. Net sodium reabsorption corresponds to the differences between primary sodium secretion rate (line A in fig. 11) and the rate of sodium excretion (line B in fig. 11). The primary sodium excretion rate is the product of sodium concentration in the coil and primary flow rate. Schulz et al. $[52,53,54]$, have shown that sodium concentration in the coil amounts to about $147 \mathrm{mEq} / \mathrm{l}$. The primary flow rate is the sum of the rates of sweat and water reabsorption calculated from the urea data [15]. Net sodium reabsorption corresponds to the vertical distance between lines $\mathrm{A}$ and $\mathrm{B}$ (fig. 11). In CFP, the net sodium reabsorption in the excretory duct is $50-75 \%$ lower than it is in CS. In CS, net sodium reabsorption increased with increasing sweat rate, whereas in CFP, a maximal value of about $10 \times 10^{-6} \mathrm{mEq} / \mathrm{l} / \mathrm{gland} / \mathrm{h}$ is approached.

A defect in sodium reabsorption in the excretory duct is eompatible with the excretory pattern of the main sweat components and explains the abnormal behavior of sodium, chloride, potassium, osmolarity, and viscosity in the sweat of patients with cystic fibrosis of the pancreas.

\section{Summary}

The excretory patterns of electrolytes and metabolites in sweat and the relations between these variables and rates of sweat production have been analyzed in pa- 
tients with cystic fibrosis of the pancreas and in normal subjects. Components in sweat appear to segregate into three groups: (1) those, the concentration of which increases with an increasing rate of sweating (sodium and chloride); (2) those, the concentration of which falls with increasing rate of sweating (potassium, calcium, lactic acid, urea, and creatinine); and (3) those, the concentration of which is independent of the rate of sweating (glucose).

The course of the sodium and the chloride curves, as well as osmolarity values, favors the assumption that the osmolar concentration of primary sweat is in the isotonic range in cystic fibrosis of the pancreas. Sodium reabsorption in the excretory duct seems to be defective in this disease.

\section{References and $\mathcal{N o t e s}$}

1. ARAkx, Y. and ANDo, S.: Urea, amino acid and ammonia in human sweat. Jap. J. Physiol. 3: 211218 (1953).

2. Åstrand, I. : Lactate content in sweat. Acta physiol.scand. 58: 359-367 (1963).

3. Beale, R.N. and Groft, D.: A sensitive method for the colorimetric determination of urea. J.clin. Path. 14: 418 (1961).

4. Brusilow, S.W. and Gordes, E.H.: Solute and water secretion in sweat. J. clin. Invest. 43: 477-484 (1964).

5. BRusilow, S.W.: An anaerobic sweat collection technique. J. Lab. clin. Med. 65: 513-517 (1965).

6. BRusilow, S.W. and Gordes, E.H.: Secretion of urea and thiourea in sweat. Amer. J. Physiol. 209: 1213-1218 (1965).

7. Brusilow, S.W.:The permeability of the sweat gland to non-electrolytes. 4th int. Conference on Gystic Fibrosis of the Pancreas (Mucoviscidosis), Berne/ Grindelwald 1966, Part I. Mod. Probl. Pediat., vol. 10, pp. 32-40 (Karger, Basel/New York 1967).

8. BRusilow, S.W.: Evidence for a non-plasma source of urea in sweat. Nature, Lond. 214: 506-507(1967).

9. Buxmer, M.G.: The concentration of urea in the thermal sweat. J. Physiol., Lond. 137: 261-266 (1957).

10. CAge, G.W. and Dobson, R. L.: Sodium secretion and reabsorption in the human eccrine sweat gland. J.clin. Invest. 44: 1270-1276 (1965).

11. CAge, G.W.; Dobson, R.L. and Waller, R.: Sweat gland function in cystic fibrosis. J.clin. Invest. 45: 1373-1378 (1966).

12. Chernick, W.S.; Barbero, G.J. and Parkins, F.M.: Studies on submaxillary saliva in cystic fibrosis. J. Pediat. 59: 890-898 (1961).

13. Clarke,J.T.; Elian, E. and Shwachman,H.: Com- ponents of sweat. Amer.J. Dis. Child. 101: 490 500 (1961).

14. Dobson, R.L.: Discussion remark: 4th int. Conference on Cystic Fibrosis of the Pancreas (Mucoviscidosis), Berne/Grindelwald 1966, Part I. Mod. Probl.Pediat., vol. 10 (Karger, Basel/New York 1967).

15. Emriah, H. M. und Ullrich, K. J. : Ausscheidung verschiedener Stoffe im Schweiß in Abhängigkeit von der Schweißflußrate. Pflügers Arch. ges. Physiol. 290: 298-310 (1966).

16. Emrigh, H.M. und Oelert, H.: pH-Wert und Gesamtammoniak im menschlichen Schweiß. Pfügers Arch. ges. Physiol. 290: 311-314 (1966).

17. Емrich, H.M. und Zwiebel, R.K.H.: Veränderungen des Lactat-Pyruvat-Quotienten im menschlichen Schweiß bei verschieden starkem Schwitzen. Pflügers Arch.ges. Physiol. 290: 315-319 (1966).

18. Emrich, H. M.; Stoll, E.; Friolet, B. ; Colombo, J.P.; Rossi, E. and Richterich, R.: Excretion of different substances in the sweat of children with cystic fibrosis and controls. Preliminary report. 4th int. Conference on Cystic Fibrosis of the Pancreas (Mucoviscidosis), Berne/Grindelwald 1966, Part I. Mod. Probl. Pediat., vol. 10, pp. 58-73 (Karger, Basel/New York 1967).

19. Emrich, H.M.; Stoll, E.; Colombo, J.P. und Trachsex, J.: Chlorid Mikro Elektrotitration mit dem Beckman Mikrotitrator Modell 153. Z.klin. Chem. 6: 218-219 (1968).

20. Gercken, G.: Die quantitative enzymatische Dehydrierung von $\mathrm{L}(+)$-Lactat für die Mikroanalyse. Hoppe-Seylers Z. physiol. Chem. 320: 180-186 (1960).

21. Gibson, L. E. and Cooke, R. E. : A test for concentration of electrolytes in sweat in cystic fibrosis of the pancreas utilizing pilocarpine by iontophoresis. Pediatrics 23: 545-549 (1959).

22. Grbson, L. E. and di Sant'Agnese, P.A.: Studies of salt excretion in sweat. J. Pediat. 62: 855-867(1963).

23. Gochberg, S.H. and Cooke, R. E.: Physiology of the sweat gland in cystic fibrosis of the pancreas. Pediatrics 18: 701-715 (1956).

24. Grand, R.J.; di Sant'Agnese, P.A.; Talamo, R. C. and Pallavicini, J. C.: The effects of exogenous aldosterone on sweat electrolytes. I. Normal subjects. J. Pediat. 70: 346-356 (1967).

25. Grand, R.J.; di Sant'Agnese, P.A.; Talamo, R. C. and Pallavicini, J. C. : The effects of exogenous aldosterone on sweat electrolytes. II. Patients with cystic fibrosis of the'pancreas. J. Pediat. 70: 357-368 (1967).

26. Herrmann, F. and Mandol, L.: Studies of $\mathrm{pH}$ of sweat produced by different forms of stimulation. J.invest. Derm. 24: 225-246 (1955). 
Sweat composition in relation to rate of sweating in patients with cystic fibrosis of the pancreas 477

27. Heuss, E. : cit. Talbert, G. A. : Effect of work and heat on hydrogen ion concentration of the sweat. Amer.J. Physiol. 50: 433-442 (1919).

28. Ітон, S.; Fujishiro, I.; Sughi, T. and Shrmokata, $\mathrm{K}$. : The secretion of sugar and its intermediate substances in sweat and saliva. Jap. J. Physiol. 3: 10-17 (1952).

29. Komives, G. K.; Robinson, S. and Roberts, J.T. : Urea transfer across the sweat glands. J. appl. Physiol. 21: 1681-1684 (1966).

30. LADELL, W.S.S.: Creatinine losses in the sweat during work in hot humid environments. J. Physiol. 106: 237-244 (1947).

31. Lobeck, G.C. and Huebner, D. : Effect of age, sex and cystic fibrosis on the sodium and potassium content of human sweat. Pediatrics 30: 172-179 (1962).

32. LoвEck, G.C.: Cystic fibrosis of the pancreas; in The metabolic basis of inherited disease, 2nd ed. (ed. Stanbury, J.B.; Wyngaarden, J.B. and FredRickson, D.S.), pp.1300-1317 (McGrawHill, New York 1966).

33. Lobeck, G.C. and McSherry, N.R.: The ionic composition of pilocarpine induced sweat in relation to gland output during aging and in cystic fibrosis. 4th int. Conference on Cystic Fibrosis of the Pancreas (Mucoviscidosis), Berne/Grindelwald 1966, Part I. Mod. Probl. Pediat., vol. 10, pp.41-57 (Karger, Basel/New York 1967).

34. Lobitz, W. G., Jr., and Osterberg, A. E. : Chemistry of palmar sweat. III. Reducing substances (glucose). Arch. Derm. Syph., Chic. 56:819-826 (1947).

35. Lobitz, W. G., Jr., and Osterberg, A. E.: Chemistry of palmar sweat. IV. Urea. Arch. Derm. Syph., (Chic.) 56: 827-833 (1947).

36. Lobrtz, W. G., Jr., and MAson, H.L.: Chemistry of palmar sweat. VII. Discussion of studies on chloride, urea, glucose, uric acid ammonia nitrogen and creatinine. Arch.Derm.Syph., Chic. 57: 907-915 (1948).

37. Marchionini, A.: DieWasserstoff-Ionenkonzentration des Schweißes. Klin. Wschr. 8: 924-926 (1929).

38. Marchioninx, A.: Untersuchungen über die Wasserstoff-Ionenkonzentration der Haut. Arch.Derm. Syph., Berlin 158: 290-333 (1929).

39. Marmar, J.; Barbero, G.J. and Subinga, M. S.: The pattern of parotid gland secretion in cystic fibrosis of the pancreas. Gastroenterology 50: 551556 (1966).

40. Matrenheimer, H.: Mikromethoden für das klinisch-chemische und biochemische Laboratorium, 2.Aufl., pp. 14-16 (de Gruyter, Berlin 1966).

41. Mitchell, H.H.; Hamilton, T.S. and Haines, W.T.: The dermal excretion under controlled environmental conditions of nitrogen and minerals in human subjects, with particular reference to calcium and iron. J. biol. Chem. 178: 345-361 (1949).

42. Pallavicini, J. G.; Gabriel, O.; Di Sant'Agnese, P.A. and Buskirk, E.R.: Isolation and characterisation of carbohydrate protein complexes from human sweat. Ann. N.Y.Acad. Sci. 106: 330-338 (1963).

43. Ramsax, J.A. and Brown, R.H.J. : Simplified apparatus and procedure for freezing point determination upon small volumes of fluid. J. sci. Instrum. 32: 372-375 (1955).

44. Ramsay, J.A.; Brown, R.H.J. and Croghan, P.G.: Electrometric titration of chloride in small volumes. J. exp. Biol. 32: 822-829 (1955).

45. Richterich, R. und Colombo, J. P.: Vereinfachte enzymatische Bestimmung der Blut-Glucose mit 20 Mikroliter Blut. VII. Mitteilung über Ultramikromethoden im klinischen Laboratorium. Klin. Wschr. 40: 1208-1211 (1962).

46. Richterich, R. and Friolet, B.: The effect of acetazolamide on sweat electrolytes in mucoviscidosis. Metabolism 12: 1112-1121 (1963).

47. Richterich, R.: Klinische Chemie, Theorie und Praxis, pp.40-42 (Karger, Basel/New York 1965).

48. Roberts, G.B.S.: Fundamental defect in fibrocystic disease of the pancreas. Lancet $i i: 964-965$ (1959).

49. Robinson, S. and Robinson, A.H.: Chemical composition of sweat. Physiol. Rev. 34: 202-220 (1954).

50. Sant'Agnese, P.A. di; Darling, R.C.; Perera, G.A. and SheA, E.: Abnormal electrolyte composition of sweat in cystic fibrosis of the pancreas. Pediatrics 12: 549-563 (1953).

51. Sanr'Agnese, P.A. dr; Talamo, R. G.; Grand, R.J. and Pallavicini, J. G.: Effect of aldosterone on sweat in normal subjects and patients with cystic fibrosis; in Research on pathogenesis of cystic fibrosis of pancreas (ed. SANT'AGnese, P.A. DI). Proceedings of the Third International Conference, Bethesda, pp. 189-207 (1964).

52. Schulz, I.; UllrRich, K.J.; Frömter, E.; EmRIGi, H.M.; Frick, A.; Hegel, U. and Holzgreve, H.: Micropuncture experiments on human sweat gland; in Research on pathogenesis of cystic fibrosis of pancreas (ed. SAnt'Agnese, P.A. Dr). Proceedings of the Third International Conference, Bethesda, pp. 136-146 (1964).

53. Schulz, I.; Ullrich, K.J.; Frömter, E.; HolzGReVE, H.; FRICK, A. und HegeL, U.: Mikropunktion und elektrische Potentialmessung an Schweißdrüsen des Menschen. Pflügers Arch.ges. Physiol. 284: 360-372 (1965).

54. Schulz, I. and Peter, G.: Micropuncture studies of the abnormality in sweat formation in cystic fibrosis (CF). Fed. Proc. 26: 287 (1967). 
55. Schwartz, I. L. and Thaysen, J.H.: Excretion of sodium and potassium in human sweat. J.clin. Invest. 35: 114-120 (1956).

56. Schwartz, I.L.; Thaysen, J.H. and Dole, V.P.: Urea excretion in human sweat as a tracer for movement of water within the gland. J. exp. Med. 97: 429-437 (1953).

57. Seutter, E. and Mali, J.W.H.: Mucopolysaccharides in seat. Clin. chim. Acta 12: 17-21 (1965).

58. Shuster, S.; McKendrick, T. and Stammers, M. : The site of the sweat gland defect in fibrocystic disease. Brit.J. Derm. 77: 105-109 (1965).

59. Sibinga, M.S. and Barbero, G.J.: Studies in the physiology of sweating in cystic fibrosis. I. Experimental sweat gland fatigue. Pediatrics 27: 912-920 (1961).

60. Sibinga, M.S. and Barbero, G.F.: Sweat sodium content and flow rate in cystic fibrosis of the pancreas. J. appl. Physiol. 18: 1226-1230 (1963).

61. SLEGERS, J.F. G.: The mechanism of eccrine sweatgland function in normal subjects and in patients with mucoviscidosis. 164th Meeting Netherl. Soc. Derm., Amsterdam 1963. Dermatologica (Basel) 127: 242-254 (1963).

62. Slegers, J.F.G.: The mechanism of sweat-secretion. Pflügers Arch. ges. Physiol.279: 265-273(1964).

63. SLEGERs, J.F. G.: The influx and outflux of sodium in the sweat gland. 169th Meeting Netherl. Soc. Derm., Nijmegen 164. Dermatologica (Basel) 132: 152-174 (1966).

64. Slegers, J. F. G. : Patho-physiological studies of the sweat gland. Pflügers Arch.ges. Physiol. 290: 231236 (1966).

65. SLegGeRs, J.F. G.: A mathematical approach to the two-step reabsorption hypothesis. 4th int. Conference on Cystic Fibrosis of the Pancreas (Mucoviscidosis), Berne/Grindelwald 1966, Part I. Mod. Probl.Pediat., vol.10, pp. 74-88 (Karger, Basel/ New York 1967).

66. Stot, C.: Plasma creatinine determination. Scand. J.clin. Lab. Invest. 17: 381-387 (1965).

67. Sмгтн, H.W.: The kidney, structure and function in health and disease, pp.97-101 (Oxford University Press, New York 1951).

68. Thaysen, J.H.: Handling of alkali metals by exocrine glands other than the kidney; in The alkali metal ions in biology. Handbuch der experimentellen Pharmakologie XIII, pp. 424-507 (Springer, Berlin/Göttingen/Heidelberg 1960).

69. Emrich, H. M.; Stoll, E.; Frioler, B.; Colombo, J.P.; Righteriah, R. and Rossi, E.: Unpublished data.

70. This investigation was supported by the Schweizerischer Nationalfonds zur Förderung der wissenschaftlichen Forschung, Project No.4070.

71. We thank Miss Luise WAGNeR for her technical assistance and Mr. Rudolf STUCKI for drawing the figures.

72. Requests for reprints should be addressed to: Ettore Rossi, M.D., Prof., Department of Pediatrics, University of Berne, Inselspital, 3008 Berne (Switzerland). 